\title{
SCANNINING ELECTRON MICROSCOPIC EVALUATION OF THE EFFECT OF BORON AND FISH OIL ON HEALING OF EXTRACTION SOCKETS IN RATS
}

\author{
Omnia M. Abd El Fatah ${ }^{2}{ }_{M D S}$, Salwa Abd El Samad ${ }^{2} P h D$, Azza Koura ${ }^{2} P h D$, Dina A. \\ $\mathrm{Nagy}^{3} \mathrm{PhD}$.
}

\begin{abstract}
INTRODUCTION: Great incidence of complications have been reported tooth extraction. Many materials and drugs were used previously to cover extraction socket in an attempt to enhance healing or prevent post-operative complications. Several studies suggested that Boron and fish oil affect many of the biological processes during bone healing by influencing cell membrane function. Thus, they affect cellular responses to cytokines and hormones, including those involved in bone growth and turnover in rats.

OBJECTIVE: of the study: To evaluate the effect of boron and fish oil on alveolar bone healing after tooth extraction in rats using Scanning Electron Microscope, Energy Dispersive x-ray analysis [EDXA] and serum alkaline phosphatase analysis.

MATERIALS AND METHODS: forty-five adult male albino rats (120-150 gm in weight) were used in this study. Extraction of the lower $1^{\text {st }}$ molar was performed in all animals then they were randomly divided into 3 equal groups; Group I (control) including 15 rats fed on normal diet, Group II (boron) including 15 rats receiving normal diet and boron supplementation ( $3 \mathrm{mg} / \mathrm{kg}$ boron diluted in $3.5 \pm 4 \mathrm{ml}$ distilled water) daily, Group III (fish oil) including 15 rats receiving normal diet and fish oil supplementation $(65 \mathrm{mg} / \mathrm{kg}$ fish oil) daily. The animals were sacrificed after 2 weeks and the effect of boron and fish oil was evaluated using Scanning Electron Microscope, Energy Dispersive x-ray analysis and Serum alkaline phosphatase level analysis. The data obtained was tabulated and subjected to statistical analysis.

RESULTS: After 2 weeks of extraction, scanning Electron Microscopic results revealed an increase in trabecular bone thickness with regular bone surface, and uniform osteocyte lacunae in Group II (boron) in comparison to group I (control ) and Group III (fish oil) and these results were proved by EDXA which showed increase in Ca level in group II than group I and group III. On the other hand, serum alkaline phosphatase analysis showed that group III (fish oil) has the higher level of ALP after 2 weeks of the experiment.
\end{abstract}

CONCLUSION: Boron and fish oil systemic administration have a positive effect on socket healing and bone structure and composition in rats. KEYWORDS: Extraction socket, Alveolar bone, Bone healing, Boron, Fish oil.

RUNNING TITLE: Boron and fish oil in socket healing.

1 Assistant lecturer of Oral Biology, Faculty of Dentistry, Pharos University, Alexandria, Egypt.

2 Professor of Oral Biology, Faculty of Dentistry, Alexandria University, Alexandria, Egypt.

3 Assistant Professor of Oral Biology, Faculty of Dentistry, Alexandria University, Alexandria, Egypt.

*Corresponding author

E-mail: dentist.omnia.magdy@hotmail.com

\section{INTRODUCTION}

Bone is a dynamic tissue that provides locomotion, muscle attachment and protection of internal organs. In addition, it undergoes frequent remodeling with a specific end goal to replace old, damaged bone, by new bone (1).

Alveolar bone is a specialized part of the mandibular and maxillary bones that supports the roots of the teeth and serves as a fibrous attachment for the periodontal ligament fibers. By resorption and deposition, it also compensates for tooth movement (2).

Tooth extraction is a routine dental procedure that can be defined as the removal of teeth from the dental alveolus (socket) in the alveolar bone. The extraction of a tooth initiates a series of reparative processes involving both hard tissue (i.e. alveolar bone) and soft tissues (periodontal ligament, gingiva) (3).

The biological events occurring during the healing of an extraction socket and their chronological sequence have been studied in different animal models, according to the existing literature, the healing process can be divided into: inflammatory, reparative, remodeling and healing phase of the oral epithelium (4).

Within the first week after tooth removal, blood clot that first filled the socket space is almost entirely remodeled and replaced with granulation tissue. After 1 week of tissue modeling, deposition of mineralized tissue begins. Within 68 weeks of healing, most of the granulation tissue is replaced 
by woven bone which also dominate in the late phase of healing (12-24 weeks) (4).

After tooth extraction, bone resorption occurs in 2 phases: During the first phase, bundle bone is rapidly resorbed and replaced with woven bone leading to the greatest amount of bone loss to occur in the horizontal dimension mainly on the facial aspect of the ridge. There is also loss of vertical ridge height (5).

During the second phase, the outer surface of the alveolar bone is remodeled causing an overall horizontal and vertical tissue contraction, decreased blood supply, and localized inflammation might play important roles in bone resorption. Resorption rate of the alveolar ridges is faster during the first six months following the extraction and proceeds at an average of $0.5-1.0 \%$ per year for the entire life (5).

Alveolar bone is dependent upon the presence of teeth for its preservation. Consequently, the alveolar ridge is progressively reduced following the extraction of teeth. Thus, preventing or minimizing alveolar bone loss after tooth extraction is a major clinical challenge, Preservation of alveolar bone volume following tooth extraction facilitates subsequent placement of dental implants and leads to an improved esthetic and functional prosthodontic result (6).

Many materials and drugs were previously used in an attempt to enhance healing of extraction socket or to prevent post-operative complications associated with extractions. However, studying the effect of natural products as herbs, nutritional elements and dietary supplementations always remain under concern (7).

Nutrition is an important modifiable factor in the development and maintenance of bone mass and regulation of bone healing process. Dietary components, such as protein, vitamins, and trace elements are required for normal bone metabolism. Beside major components essential for bone mineralization such as calcium, phosphorus and vitamin $\mathrm{D}$, other nutrients like boron and fish oil have beneficial role, too (8).

Boron is a bioactive element that has beneficial, if not essential, effects on trabecular microarchitecture and cortical bone strength. Emerging evidence indicates that boron plays a role in bone formation and maintenance. Several findings showed also that boron deficiency results in altered bone healing because of a marked reduction in osteogenesis (9).

Many Studies showed that boron plays an essential role in keeping bones and joints functioning optimally and supports bone density by helping the body to metabolize important minerals such as calcium \& magnesium. Boron also plays an important role in osteogenesis, and its deficiency has been found to adversely impact bone development and regeneration (9).

Since 1990, boron has been shown to significantly improve wound healing, as application of a $3 \%$ boric acid solution to deep wounds reduced the time required for healing by two-thirds. In 2000, in vitro research using human fibroblasts showed that a boric-acid solution improved wound healing through its action on the fibroblast in the tissue extracellular matrix (10).

Fish oil is a common term used to refer to two kinds of fatty acids: eicosapentaenoic acid (EPA) and docosahexaenoic acid (DHA). EPA is a precursor to chemicals involved in blood clotting and inflammation (prostaglandin-3, thromboxane-2, and leukotriene-5). While DHA is a major component of the human retina, sperm, and cerebral cortex (11).

Fish oil plays a critical role in the regulation of a variety of biological processes including bone metabolism. They affect bone metabolism through their effect on calcium balance, osteoblastogenesis and osteoblast activity, and decreasing the inflammatory cytokines such as interleukin-1 (IL-1), interleukin-6 (IL-6), and tumor necrosis factor alpha (TNF-alpha). Animal studies have shown that a higher dietary omega-3/omega- 6 fatty acids ratio is associated with beneficial effects on bone healing (12).

Bone healing after tooth extraction in rats was proven to be considered as a suitable experimental model to study bone remodeling and mineralization. Thus, the current study was done to evaluate the effects of boron and fish oil on bone healing by using the albino rats as a model.

\section{MATERIALS AND METHODS}

This study was conducted following the ethical guidelines for conduct of research on experimental animals, by the Faculty of Dentistry, Alexandria University (IRB NO: 00010556-IORG 0008839).

Forty-five adult male albino rats weighing 120-150 gm were used in this study. Animals were obtained from the animal house of Medical Research Institute, Alexandria University. They were housed in specially designed wire mesh bottom cages, five animals per cage and kept under the same nutritional and environmental conditions $(13,14)$.

Following extraction, rats were randomly divided into 3 equal groups, 15 rats each. In order to minimize risk of confounding, random allocation must be truly done, by using a computer-generated random sequence of numbers to assign treatment status (15).

Group I: (Control group) including 15 rats fed on normal diet.

Group II: (boron group) including 15 rats receiving boron (3 $\mathrm{mg} / \mathrm{kg}$ boron diluted in $3.5 \pm 4 \mathrm{ml}$ distilled water) daily using oral gavage.

Group III: (fish oil group) including 15 rats receiving fish oil $(65 \mathrm{mg} / \mathrm{kg})$ daily using oral gavage.

\section{Inclusion criteria:}

The rats in this study were matched with age, weight, sex, unified type of diet, and housing.

\section{Exclusion criteria:}

Rats included in any previous experimental study or presence of any illness or wound were excluded.

\section{MATERIALS}

Boron

Boron 3 mg - 100 Vegetarian Capsules by Life Extension. Fish oil

Nature Made Fish Oil -- 1200 mg - 180 Liquid Soft gels capsules. 


\section{Surgical instruments}

Scalpel, tissue retractor, mouth prop, scissor, tweezer, surgical elevator, and lower remaining root extraction forceps. Needle holder and black silk suture were used.

\section{Anesthesia}

Ketamine chloride and xylazine

\section{METHODS}

\section{Pre-operative preparation}

Animals were given antibiotics, spiramycin (7 mg/kg) (Rovapex provided by apox phara co. 13, AFL atoun St. Heliopolis, Cairo, Egypt) and metronidazole (12 mg/kg) (Flagyl provided by santiaventis Co. 3, EL Massaneh. St. Zietoun, Cairo, Egypt) orally three days before extraction. Then animals were starved for 12-24 hours and maintained in thirst for 6 hours prior to anesthesia (16).

\section{Surgical extraction}

All animals were anesthetized by intraperitoneal administration of a $4: 1$ solution of ketamine chloride and xylazine at a dose of $0.15 \mathrm{ml}$ per $100 \mathrm{~g}$ of body weight. Then, the surgical site was disinfected using iodine swab and atraumatic extraction of the lower right $1^{\text {st }}$ molar was performed by the same operator with the same technique in all animals. The soft tissues in all groups were sutured by $4-$ 0 Vicryl sutures using a cross-mattress technique to achieve site stability (16).

All the animals received the same course of antibiotic spiramycin $(7 \mathrm{mg} / \mathrm{kg})$ and metronidazole $(12 \mathrm{mg} / \mathrm{kg})$ orally for five days after surgery every eight hours. Intramuscular analgesic Cataflam (Diclofenac Potassium 1.5\%, Novartis, Ramadan City, Egypt) was given to the animals every eight hours for the first two days. The animals were observed daily to assess the presence or absence of any signs of inflammation or infection.

Following the extraction, the animals were randomly divided into 3 groups; each one composed of 15 rats. Boron and fish oil were administered orally to the rats according to their different body weights in different groups using oral gavage.

\section{Blood samples collection (17)}

Two blood samples were drawn from rats in all groups at the beginning of the experiment and after 2 weeks from extraction before scarification. Blood samples were collected from paraorbital sinus puncture, where the collective device was kept clean to avoid vascular damage or introduction of tissue into collected blood that may activate coagulation and to prevent hemolysis of erythrocytes.

\section{Animals' sacrifice}

Animals were sacrificed by the end of the $2^{\text {nd }}$ week after extraction and the mandibles were dissected out and the right halves were separated and fixed in $4 \%$ formaldehyde with $1 \%$ glutaraldehyde for the Scanning Electron Microscopic examinations and Energy Dispersed x-ray analysis (EDXA).

Scanning Electron Microscope (SEM) (Faculty of science, Alexandria university) (18)

New bone formation was evaluated by SEM at 2 weeks after extraction. The specimens were fixed in $4 \%$ formaldehyde with $1 \%$ glutaraldehyde and the areas of extracted socket were split at the mandibular first molar region.

The specimens were rinsed in phosphate buffer for 10 minutes and then dehydrated by passing through series of $50 \%, 70 \%$ and $95 \%$ ethyl alcohol for 10 minutes each and then in absolute alcohol for two changes of one-hour period. After dehydration, the specimens were dried at the critical point and mounted using silver paint on the specimen holder then coated with gold through ion sputtering device.

After coating, the samples were examined by the Jeol scanning microscope (JSM-5300). The accelerating voltage applied changed from one specimen to another depending on received picture on display screen, which was usually $25 \mathrm{Kv}$.

Energy Dispersive x-ray Analysis (EDXA) (Faculty of science, Alexandria university) (18)

From each dissected jaw, a block of the alveolar bone sectioned at the molar region and prepared for Energy Dispersive x-ray microanalysis to compare the different percentage of different elements in alveolar bone. The specimens were ground and polished using diamond paste to be $(1 \mu \mathrm{m}$ size). Then, they were washed out under running water, dehydrated and air dried. Surface of the bone was exposed to Xray analysis using the EDX system.

\section{Serum alkaline phosphatase (ALP) (17)}

Serum (ALP) test was done at the end of the experimental period as a marker for bone formation in the different groups by Colorimetric Method.

\section{Statistical analysis (19)}

Data of EDXA analysis and serum alkaline phosphatase analysis were fed to the computer and analyzed using IBM SPSS software package version 20.0. Quantitative data were described using range (minimum and maximum), mean, standard and median. The distributions of quantitative variables were tested using F-test (ANOVA). Significance of the obtained results was judged at the 5\% level.

\section{RESULTS}

The results obtained from this study included the followings:

1. Scanning Electron Microscope (SEM).

2. Energy Dispersive X-ray Analysis (EDXA).

3. Serum alkaline phosphatase analysis.

1. Scanning Electron Microscopic (SEM) Results:

2 weeks interval

\section{Group I: (control group)}

The surface topography of the alveolar bone at the socket at the molar region in control group revealed a smooth bone surface with fine irregularities. Socket borders showed regular and uniform outline (Fig. 1). At higher magnification, the interconnecting bone trabeculae appeared surrounding numerous variable sized osteocyte spaces and loosely attached collagen bundles. Also, multiple resorptive areas were noticed on the bone surface (Fig. 2).

\section{Group II: (boron group)}

The surface topography of the alveolar bone at the molar region in boron group revealed evidence of new bone formation at the wall of the socket where the newly formed bone trabeculae formed a thick and uniform network enclosing marrow spaces (Fig. 3). At higher magnification, 
thick newly formed bone trabeculae with an irregular multiple elevation and depressions of calcified bone were seen (Fig. 4).

\section{Group III: (fish oil group)}

The surface topography of the alveolar bone at the socket at the molar region in fish oil group after 2 weeks of extraction exhibited a generalized pattern of surface roughness and many irregularities of fine newly formed bone adjacent to the edges of the healing socket. Wide osteocyte lacunae surrounded by densely packed collagen bundles were also noticed (Fig. 5). At higher magnification, surface examination of this group revealed a network of thin, ramified bone trabeculae enclosing marrow spaces and osteocyte lacunae (Fig. 6).

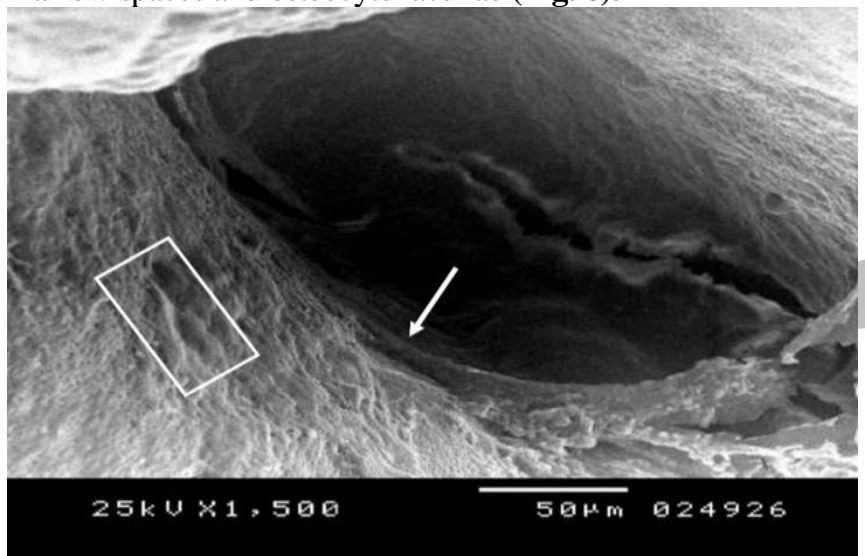

Figure (1): Scanning electron micrograph (SEM) of the healing socket horizontal view at 2 weeks (control group) showing smooth bone surface with fine irregularities (arrows) (X 1500).

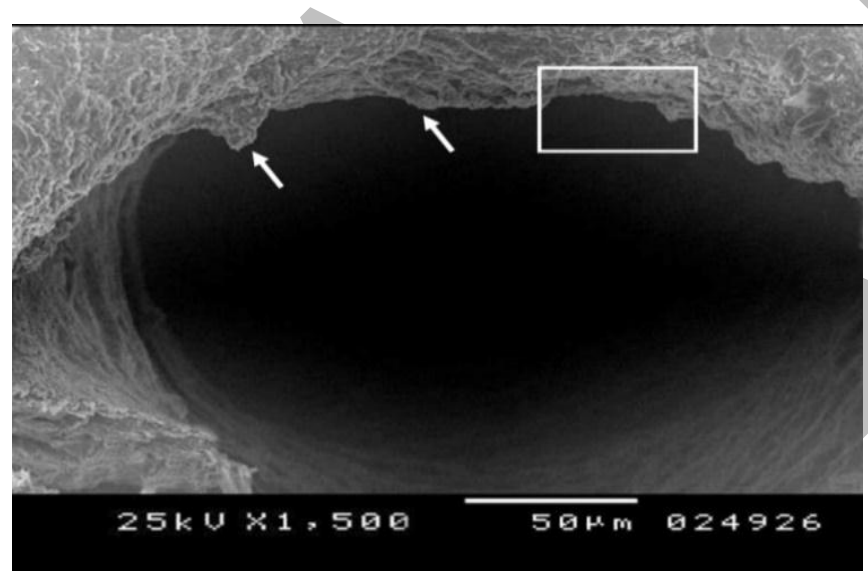

Figure (2): Scanning electron micrograph (SEM) of at 2 weeks (boron group) showing a thick bone trabecula surrounding the extraction socket (arrows) (X 1500 ).

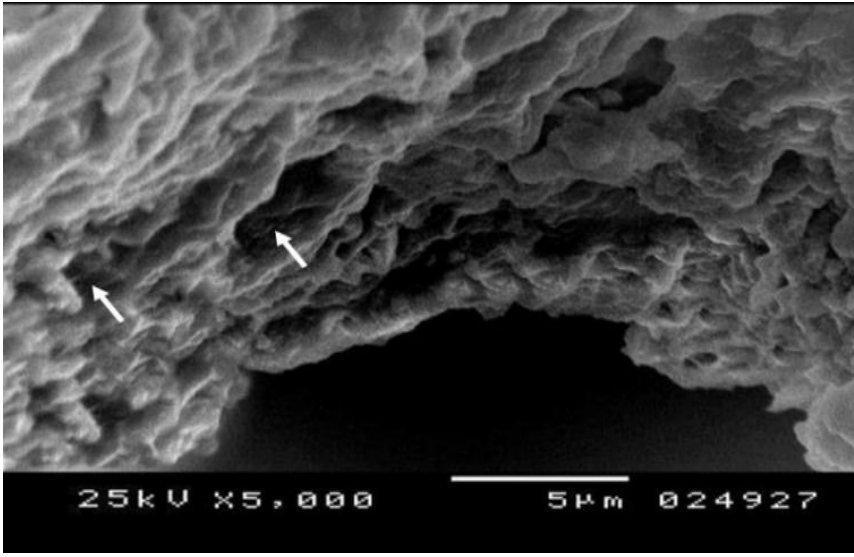

Figure (3): Higher magnification of the inset in the previous micrograph showing thick newly formed bone trabeculae of the healing socket. Note the irregular bone surface with multiple elevations and depressions of variable depths (arrows) (X 5000).

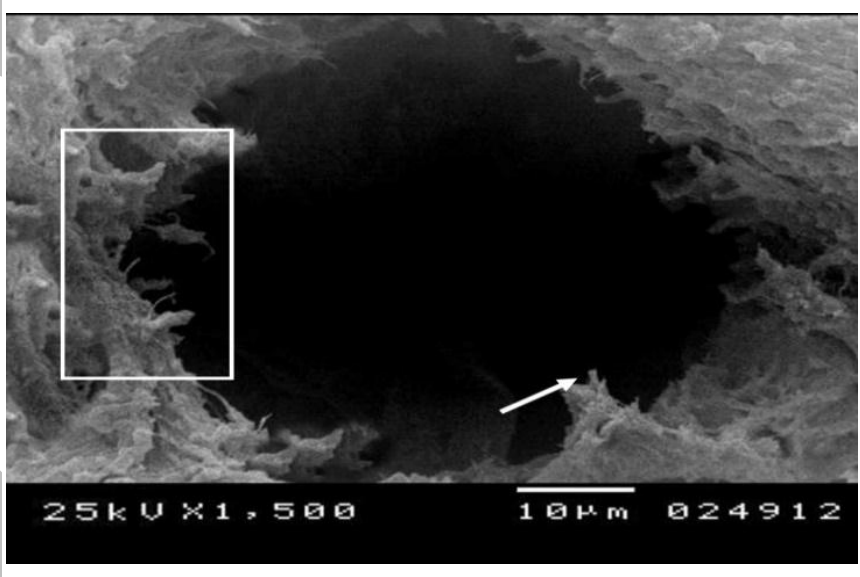

Figure (4): Scanning electron micrograph (SEM) of the healing extraction socket horizontal view at 2 weeks (fish oil group) showing new bone formation arising from the border of the socket (arrow) and wide marrow spaces (X 1500).

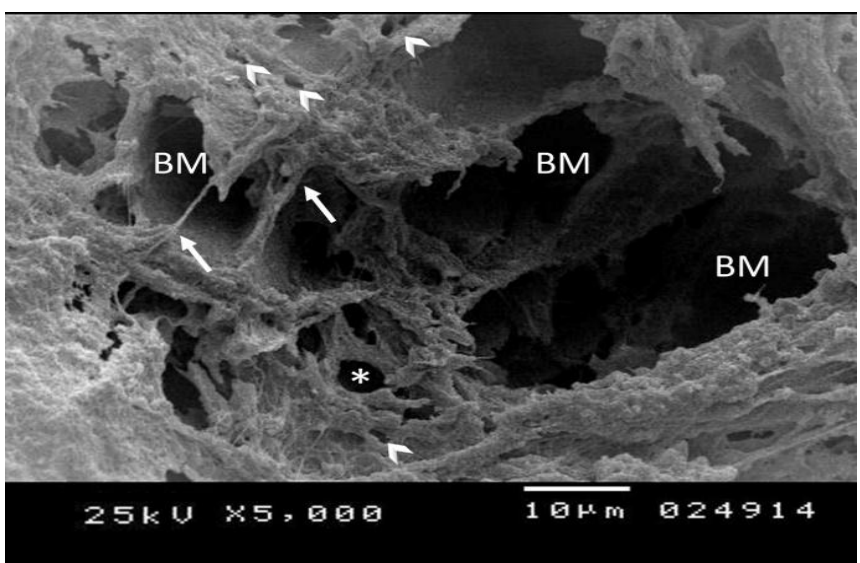

Figure (5): Higher magnification of the inset in the previous micrograph showing network of thin bone trabeculae (arrow) enclosing bone marrow spaces (BM) and nutritive canals (asterisk). (x5000) 


\section{Energy Dispersive x-ray Analysis (EDXA): (Table 1)}

Table (1) shows comparison between the three groups [group I (control), group II (boron) and group III (fish oil)] according to percentages of calcium and phosphorous after 2 weeks of extraction and these data was summarized by means and standard deviation. It was evident that when the value of calcium increases, there was a decrease in the phosphorous value (inverse relationship).

Regarding the calcium level, group II (boron) showed the highest value $(75.2 \pm 0.6)$ followed by group III (fish oil) $(65.4 \pm 1.5)$ while group I (control) showed the lowest value $(64.46 \pm 0.92)$.

There was statistically significant decrease in calcium level in control group in relation to boron group ( $\mathrm{p}_{1}$ calcium $<0.001$ ), while there was no statistically significant difference between control group and the fish oil group regarding the calcium level $\left(\mathrm{p}_{2}\right.$ calcium $\left.=0.361\right)$, In addition, the difference between boron group and fish oil group was significant $\left(\mathrm{p}_{3 \text { calcium }}<0.001\right)$.

Regarding the phosphorous level, control group showed the highest value $(43.6 \pm 2.2)$ followed by fish oil group $(37.3 \pm$

1.3) while boron group showed the lowest value (30.8 \pm 0.9$)$.

There was statistically significant increase in phosphorous level in control group in relation to boron group ( $\mathrm{p}_{1}$ phosphorous $<0.001$ ), and also significant difference between control group and the fish oil group regarding the phosphorous level ( $\mathrm{p}_{2}$ phosphorous $<0.001$ ), In addition, the difference between boron group and fish oil group was significant $\left(\mathrm{p}_{3}\right.$ phosphorous $\left.<0.001\right)$.

\section{Serum alkaline phosphatase level (Table 2)}

Table (2) show the comparison between the three groups of the study [group I (control), group II (boron) and group III (fish oil) regarding the Serum alkaline phosphatase level of the rats at day 1 and 2 weeks after extraction.

Table (1): Comparison between the three studied groups according to $P$ and $\mathrm{Ca}$ level after two weeks.

\begin{tabular}{|c|c|c|c|c|c|c|}
\hline & & Group I & Group II & Group III & 1 & $\bar{p}$ \\
\hline & Week 2 & & & & & \\
\hline & \begin{tabular}{|l|} 
Median \\
(Min. -
\end{tabular} & $54.5(63.2-65.6)$ & $75.6(74.2-75.6)$ & $65.2(63.7-67.6)$ & 154.911 & 0.001 \\
\hline $\mathbf{C a}$ & $\begin{array}{l}\text { Max.) } \\
\text { Mean }\end{array}$ & & $75.2 \pm$ & $65.4 \pm 1.5$ & & \\
\hline & $\begin{array}{l}\text { et. grps } \\
\text { ens }\end{array}$ & \multirow{2}{*}{\multicolumn{3}{|c|}{$\underset{\text { calcium }}{\mathrm{p}_{1 \text { calcium }}<0.001^{*}}=0.001^{*}, \mathrm{p}_{2 \text { calcium }}=0.361, \mathrm{p}_{3}$}} & & \\
\hline & & & & & & \\
\hline \multirow{8}{*}{$\mathbf{P}$} & Week 2 & & & & & \\
\hline & Median & $44.3(40.4-44.9)$ & $30.6(26.4-30.8)$ & $37.6(35.6-38.8)$ & 340.923 & 0.001 \\
\hline & Max.) & & & & & \\
\hline & Mean & $43.6 \pm 2.2$ & $30.8 \pm 0.9$ & & & \\
\hline & & & & & & \\
\hline & $\begin{array}{l}\text { Sig. } \\
\text { bet. }\end{array}$ & \multirow{3}{*}{\multicolumn{3}{|c|}{$\begin{array}{c}\mathrm{p}_{1 \text { phosphorous }}<0.001^{*}, \quad \mathrm{p}_{2} \text { phosphorous } \\
<0.001^{*}, \\
\mathrm{p}_{3 \text { phosphorous }}<0.001^{*}\end{array}$}} & & \\
\hline & grps & & & & & \\
\hline & & & & & & \\
\hline
\end{tabular}

F: $\mathrm{F}$ for ANOVA test, Pairwise comparison bet. each 2 groups were done using Post Hoc Test (Tukey)

$\mathrm{p}$ : $\mathrm{p}$ value for comparing between the studied groups $\mathrm{p}_{1}$ : $\mathrm{p}$ value for comparing between group I and group II $\mathrm{p}_{2}$ : $\mathrm{p}$ value for comparing between group I and group III $\mathrm{p}_{3}$ : $\mathrm{p}$ value for comparing between group II and group III $*$ : Statistically significant at $\mathrm{p} \leq 0.05$
Table (2): Comparison between the studied groups according to serum alkaline phosphatase level

\begin{tabular}{|c|c|c|c|c|c|}
\hline \begin{tabular}{|c|} 
Serum \\
alkaline \\
phosphatase \\
level (mg/dl)
\end{tabular} & Group I & Group II & Group III & $\mathrm{F}$ & $\mathrm{p}$ \\
\hline Day 1 & & & & \multirow{4}{*}{0.210} & \multirow{4}{*}{0.888} \\
\hline Min. - Max. & $200.0-209.0$ & $202.0-210.0$ & $200.0-209.0$ & & \\
\hline Mean $\pm \mathrm{SD}$ & $203.60 \pm 3.36$ & $205.0 \pm 3.32$ & $204.0 \pm 3.87$ & & \\
\hline Median & 203.0 & 205.0 & 203.0 & & \\
\hline Week 2 & & & & \multirow{4}{*}{$103.944^{*}$} & \multirow{4}{*}{$\begin{array}{c}<0.00 \\
1^{*}\end{array}$} \\
\hline Min. - Max. & $220.0-229.0$ & $250.0-295.0$ & $330.0-350.0$ & & \\
\hline Mean $\pm \mathrm{SD}$ & $223.60 \pm 3.78$ & $282.60 \pm 18.41$ & $341.20 \pm 8.79$ & & \\
\hline Median & 224.0 & 290.0 & 340.0 & & \\
\hline $\mathrm{p}_{\text {Control }}$ & & $<0.001^{*}$ & $<0.001^{*}$ & & \\
\hline Sig. bet. grps & \multicolumn{5}{|c|}{$\mathrm{p}_{1}<0.001^{*}$} \\
\hline
\end{tabular}

F: F for ANOVA test, Pairwise comparison bet. Each 2 groups were done using Post Hoc Test (Tukey)

$\mathrm{p}$ : $\mathrm{p}$ value for comparing between the studied groups

pControl: $p$ value for comparing between group I and each other group $\mathrm{p}_{1}$ : $\mathrm{p}$ value for comparing between group II and group III

\section{Day 1 after extraction}

The mean values for Serum alkaline phosphatase level were $203.60 \pm 3.36,205.0 \pm 3.32,204.0 \pm 3.87$, respectively. It was evident that the value was almost the same in the three groups (this reading was considered a base line data for the animals).

The difference among the three groups as regarding mean Serum alkaline phosphatase level in $\mathrm{mg} / \mathrm{dl}$ at day 1 of extraction was not statistically significant $(\mathrm{p}=0.88)$.

\section{Week 2 after extraction}

The mean values for Serum alkaline phosphatase level were $223.60 \pm 3.78,282.60 \pm 18.41,341.20 \pm 8.79$, respectively. It was evident that the fish oil group showed the highest value.

There was a statistically significant difference between control group and both the boron group and fish oil group (pControl <0.001). Also, there was statistically significant difference between boron group and the fish oil group (P1 $<0.001)$.

\section{DISCUSSION}

Tooth extraction is the most common surgical procedure performed in dentistry. It could be described as a tissue amputation that may lead to functional, psychological, postural, and local changes. In modern dentistry, the healing process of the socket following tooth extraction has become an important topic of research, study and discussion (20).

Alveolar bone is a specialized part of the mandibular and maxillary bones that forms the primary support structure for teeth. It depends upon the presence of teeth for its preservation. Consequently, the alveolar ridge is progressively reduced following the extraction of teeth. Thus, preventing or minimizing, alveolar bone loss after tooth extraction is a major clinical challenge, which facilitates subsequent placement of dental implants and leads to an improved esthetic and functional prosthodontic result (21). 
Despite the results from the animal and human histological studies delineated a well-defined tendency of each tissue component to change over time, they also revealed great inter-individual variation in healing of the extraction socket with respect to tissue formation and maturation. The reason for this variation is presently not understood but may be linked to different factors which may be, at least in part, related to patient and site characteristics as well as surgical variables (22).

In general terms, the factors that influence healing can be categorized into local and systemic factors, many of these factors are related, and the systemic factors act through the local effects affecting healing $(22,23)$.

Nutrition is one of the most important factors that effects healing of the alveolar socket. Despite of many researches discussed the beneficial effect of fish oil on bone health, there is not enough data available about its mechanism of action. Also, the review of literature is lacking articles dealing with assessment of the effect of some trace elements like boron as dietary supplementation on the healing of extraction socket (23). So, the aim of the present study was directed to reveal the possible effect of both boron and fish oil on healing of extraction socket in albino rats.

In the present study, albino rats were chosen to investigate socket healing. Using rat as an experimental animal has many advantages including its availability, economic expenses, and healing short duration, since females are more prone for osteoporosis than males, males were chosen in the present study. This in agreement with Hassumi et al 2018 (24) who studied alveolar bone healing in rats. While, Abegao et al 2015 found that using rabbits as a model in extraction wound is better as a larger animal and also rapid healing cycle of its bone in comparison to human (25).

Incisors were not used as a model study of socket healing in order not to hinder the animal ability to eat and due to their continuous eruption that may disturb the normal process of healing. Indeed the first mandibular molar was chosen this is in contrast to the choice of Liu et al 2019 (26) who studied Socket healing after rat mandibular incisor extraction but in accordance with Zandi et al 2017who studied the Extraction socket healing in rats treated with bisphosphonate (27) .

Boron and fish oil were given systemically because it is risk to remain in position if applied directly inside the socket. Also, their systemic administration allowed to evaluate their effect when taken as oral tablets in humans. The applied dose was chosen according to Nielsen et al 2009 (28) who used boron and fish oil systematically to test their effect on bone microarchitecture and found that this dose has an effect on bone turnover without any additional toxic effects.

In the current study evaluation of bone healing was carried out at 2 weeks after extraction, which allowed the analysis of the initial stage of bone repair. This is in agreement with, Neiva et al 2009 (29) who evaluated the socket healing after 1 and 2 week and stated that its enough to observe healing of the socket. However this is in disagreement with Shrivastava et al 2018 who found that evaluation of complete bone healing reqiure around 4 and 6 weeks intervals (30).

Scanning electron microscope and energy dispersive $\mathrm{x}$ ray analysis (EDXA) were used as a diagnostic tool in the current study; SEM to evaluate bone surface regeneration and assess surface topography of the newly formed bone, while EDXA was used for the elemental analysis for calcium and phosphorous and to compare their different percentages in the newly formed bone. This in accordance with Ellingham et al 2018 who used Scanning Electron Microscopy-EnergyDispersive X-Ray (SEM/EDX) as a rapid diagnostic tool to help in the identification of burnt bone in forensic dentistry. This indicated that SEM is not only a confirmatory tool but also it could be the main method to evaluate bone topography (31).

The SEM results of the present study demonstrated that at the end of the second week after extraction, the socket of control group revealed smooth bone surface with fine irregularities, the interconnecting bone trabeculae appeared surrounding numerous variable sized osteocyte spaces and loosely attached collagen bundles. This in agreement with Guo et al 2019 who found that SEM results of healing of extraction socket at 14 day showed regular, thin, bony spicule at the healing socket with wide bone marrow spaces (32). While in contrast Capetillo, et al 2017 showed that SEM after 2 weeks of extraction, revealed that the central part of the healing socket was empty representing only granulation tissue formation (33).

The surface topography of the alveolar bone at the molar region in the boron group after 2 weeks exhibited evidence of new bone formation at the wall of the socket with a generalized pattern revealing a thick and uniform network of newly formed bony trabeculae with narrow marrow spaces and multiple osteocytes.

This is in accordance with Nielsen al 2009 who confirmed that boron promotes bone formation. The vertebral morphometric findings indicated also that boron is beneficial, if not essential, for trabecular microarchitecture that promotes bone strength. Boron was also found to increase Messenger RNA (mRNA) expression of ALP and RUNX2. Indeed, many researches have confirmed that boron regulates levels of key bone morphogenic proteins BMPs such as BMP-4, BMP-6, and BMP-7. Both BMPs and RUNX2 are essential to osteoblastic differentiation, bone formation and maintenance (28).

In fish oil group after 2 weeks of extraction a generalized pattern of surface roughness and fine irregularities of fine newly formed bone adjacent to the edges of the healing socket. Wide osteocyte lacunae surrounded by densely packed collagen bundles were also noticed indicating the rapid continuous rate of bone formation. This data is on the same line with Kesavalu et al., 2006 who stated that in a group of rats treated with omega 3 an obvious improvement in bone architecture at LM and SEM levels were evidenced (34).

This may be due to the fish oil effect on calcium balance, osteoblastogenesis and osteoblast activity, in addition 
it decreases inflammatory cytokines such as interleukin-1 (IL1), interleukin-6 (IL-6), and tumor necrosis factor alpha (TNFalpha) (34).

The elemental analysis of the current study pointed up on calcium $(\mathrm{Ca})$ and phosphorus $(\mathrm{P})$ which are the main constituents of hydroxyapatite crystals that represent the main component of the inorganic part of the bone tissue (1).

The EDX results confirmed and enforced the result of the SEM where the boron group showed the highest level of $\mathrm{Ca}$ indicating high bone density. This is in accordance with Armstrong, et al 2001 who found that Boron apparently affects bone composition and physical characteristics by influencing the presence or action of hormones involved in bone growth and turnover. In addition to its regulatory role in calcium hemostasis (35).

Alkaline phosphatase serum analysis was used as a marker for bone formation according to Sarvari et al 2015 who used it as a useful marker to evaluate lumbar bone mineral density (17). However recently it can't be considered as a specific bone marker as it could be found in liver and kidney also, it was found that Bone Specific Alkaline Phosphatase (BSAP) is the accurate marker for osteoblast activity and bone growth according to Hinge et al, 2016 (36).

The result of the serum alkaline phosphatase analysis in the current study revealed that the fish oil group has the highest level followed by the boron group and this confirms both the result of SEM and EDX analysis that fish oil has a appositive effect in accelerating healing of the socket.

As a rule, ALP enzyme is considered as an early marker of osteoblast progenitors, it increases when osteoblasts mature and deposit matrix while it declines again as osteoblasts become osteocytes Sarvari et al 2015 (37). This explains why level of ALP is lowered in boron group which may be due to that boron ability to increase the rate of bone mineralization.

Also, in accordance with Watkins et al 2003 who found that Both EPA and DHA in fish oil have been shown to promote bone specific alkaline phosphatase activity, osteoblastogenesis and bone formation and suppress osteoclastogenesis and bone resorption (38).

Finally, we recommended the use of boron and fish oil as dietary supplementation after tooth extraction, as the satisfactory repair rate of the extraction socket suggested the determining role of fish oil and boron in facilitating new bone regeneration.

\section{CONCLUSIONS}

1. Systemic administration of boron and fish oil after tooth extraction improved the early phase of bone healing

2. Boron is a bioactive element that has beneficial, if not essential, effects on trabecular microarchitecture and cortical bone strength.

3. Fish oil is an essential fatty acid that accelerates bone healing and increases osteogenesis.

4. Proper nutrition plays a vital role in the well-being of a person. Food rich in essential and trace elements like boron and fish oil have a proven role in enhancing the healing of the alveolar socket in its early stages to prevent post-operative complication.

\section{CONFLICT OF INTEREST}

The authors declare that they have no conflicts of interest.

\section{ACKNOWLEDGMENTS}

I would like to thank Prof. Dr Salwa Abd el Samad, Prof.Dr. Azza Koura, and Ass.Prof.Dr. Dina Nagui for providing support in this study.

\section{REFERENCES}

1. Avery JK, Chiego DJ. Essentials of oral histology and embryology: a clinical approach. $3^{\text {rd }}$ ed. Salt Lake City: Mosby Elsevier; 2006.

2. Creanor S, Ali K. Alveolar bone. In: Creanor S (ed). Essential Clinical Oral Biology. Ch 7. New York: John Wiley \& Sons; 2016. p.50-56

3. Steiner GG, Francis W, Burrell R, Kallet MP, Steiner DM, Macias R. The healing socket and socket regeneration. Compend Contin Educ Dent. 2008; 29:114-26.

4. Larjava H. Oral wound healing: cell biology and clinical management. Hoboken: John Wiley \& Sons; 2012.

5. Avila-Ortiz G, Elangovan S, Kramer KW, Blanchette D, Dawson DV. Effect of alveolar ridge preservation after tooth extraction: a systematic review and meta-analysis. J Dent Res. 2014; 93:950-8.

6. Horowitz RA. Preservation of Alveolar Dimensions at the Time of Tooth Extraction. In: Karateew ED (ed). Implant Aesthetics. $1^{\text {st }}$ ed. Cham, Switzerland: Springer; 2017. P.171-88.

7. Kang KL, Kim EC, Park JB, Heo JS, Choi Y. Highfrequency, low-intensity pulsed ultrasound enhances alveolar bone healing of extraction sockets in rats: A pilot study. Ultrasound Med Biol. 2016; 42:493-502.

8. Bonjour JP. Dietary protein: an essential nutrient for bone health. J Am Coll Nutr. 2005; 24:526S-36S.

9. Hakki SS, Bozkurt BS, Hakki E. Boron regulates mineralized tissue-associated proteins in osteoblasts (MC3T3-E1). J Trace Elem Med Biol. 2010; 24:243-50

10. Devirian TA, Volpe SL. The physiological effects of dietary boron. Crit Rev Food Sci Nutr. 2003; 43:219-31.

11. Block RC, Harris WS, Reid KJ, Sands SA, Spertus JA. EPA and DHA in blood cell membranes from acute coronary syndrome patients and controls. Atherosclerosis. 2008; 197:821-8.

12. Simopoulos AP. Omega-3 Fatty Acids in Inflammation and Autoimmune Diseases. J Am Coll Nutr. 2002; 21:495-505.

13. Rigalli A, Di Loreto V. Experimental surgical models in the laboratory rat. $1^{\text {st }}$ ed. CRC Press; 2016.

14. Nicklas W, Baneux P, Boot R, Decelle T, Deeny AA, Fumanelli M, et al. Recommendations for the health monitoring of rodent and rabbit colonies in breeding and experimental units. Lab Anim. 2002; 36:20-42. 
15. Muhlhausler BS, Bloomfield FH, Gillman MW. Whole animal experiments should be more like human randomized controlled trials. PLoS Biol. 2013;11: e1001481.

16. Kotsakis G, Chrepa V, Marcou N, Prasad H, Hinrichs J. Flapless alveolar ridge preservation utilizing the "socketplug" technique: clinical technique and review of the literature. J Oral Implantol. 2014; 40:690-8.

17. Sarvari BKD, Mahadev DS, Rupa S, Mastan SA. Detection of Bone Metastases in Breast Cancer (BC) Patients by Serum Tartrate-Resistant Acid Phosphatase 5b (TRACP 5b), a Bone Resorption Marker and Serum Alkaline Phosphatase (ALP), a Bone Formation Marker, in Lieu of Whole Body Skeletal Scintigraphy with Technetium99m MDP. Ind J Clin Biochem. 2015; 30:66-71.

18. Eric L, Charles E, Patrick E, David C, Dale E. Scanning electron Microscopy and X-ray microanalysis. $3^{\text {rd }}$ ed. USA: Klumer Academic Plenum publisher; 2003.

19. Kotz S, Balakrishnan N, Read CB, Vidakovic B. Encyclopedia of statistical sciences. $2^{\text {nd }}$ ed. Hoboken, NJ: Wiley-Interscience; 2006.

20. Araújo MG, Silva CO, Misawa M, Sukekava F. Alveolar socket healing: what can we learn? Periodontology 2000. 2015;68:122-34.

21. Fisher JP, Lalani Z, Bossano CM, Brey EM, Demian N, Johnston CM, et al. Effect of biomaterial properties on bone healing in a rabbit tooth extraction socket model. $\mathbf{J}$ Biomed Mater Res A. 2004; 68:428-38.

22. Pagni G, Pellegrini G, Giannobile WV, Rasperini G. Postextraction alveolar ridge preservation: Biological basis and treatments. Int J Dent. 2012; 2012:1-13.

23. Fischer V, Haffner-Luntzer M, Amling M, Ignatius A. Calcium and vitamin D in bone fracture healing and posttraumatic bone turnover. Eur Cell Mater. 2018;35:365-385.

24. Hassumi JS, Mulinari-Santos G, Fabris AL, Jacob RG, Goncalves A, Rossi AC, et al. Alveolar bone healing in rats: micro-CT, immunohistochemical and molecular analysis. J Appl Oral Sci. 2018; 26: e20170326.

25. Abegão KG, Bracale BN, Delfim IG, Santos ES, Laposy $\mathrm{CB}$, Nai GA, et al. Effects of heterologous platelet-rich plasma gel on standardized dermal wound healing in rabbits. Acta Cir Bras. 2015;30:209-15.

26. Li X, Liu X, Ni S, Liu Y, Sun H, Lin Q . Enhanced osteogenic healing process of rat tooth sockets using a novel simvastatin-loaded injectable microspherehydrogel system. J Craniomaxillofac Surg. 2019; pii: S1010-5182(18)31117-X.
27.Zandi M, Dehghan A, Mohammadi-Mofrad A, Amini P, Vahdatinia F. Short-term perioperative teriparatide therapy for the prevention of medication-related osteonecrosis of the jaw: A randomized, controlled preclinical study in rats. J Craniomaxillofac Surg. 2017; 45:275-80.

28. Nielsen FH, Stoecker BJ. Boron and fish oil have different beneficial effects on strength and trabecular microarchitecture of bone. J Trace Elem Med Biol. 2009; 23:195-203.

29. Fotek PD, Neiva RF, Wang HL. Comparison of dermal matrix and polytetrafluoroethylene membrane for socket bone augmentation: a clinical and histologic study. J Periodontol. 2009; 80:776-85

30. Shrivastava A, Shenoi R, Garg A, Vats V, Gadve V, Siddiqui A. Role of Platelet Rich Fibrin in Healing of Extraction Socket. IJCMR. 2018; 5: E6-E10.

31. Ellingham STD, Thompson TJU, Islam M. Scanning Electron Microscopy-Energy-Dispersive X-Ray (SEM/EDX): A Rapid Diagnostic Tool to Aid the Identification of Burnt Bone and Contested Cremains. J Forensic Sci. 2018; 63:504-10.

32. Guo X, Hu H, Liu Y, Bao C, Wang L. The Effect of Hemostatic Agents on Early Healing of the Extraction Socket. J Clin Periodontol. 2019.

33. Kim JH, Koo KT, Capetillo J, Kim JJ, Yoo JM, Ben Amara $\mathrm{H}$, et al. Periodontal and endodontic pathology delays extraction socket healing in a canine model. J Periodontal Implant Sci. 2017; 47:143-53.

34. Kesavalu L, Vasudevan B, Raghu B, Browning E, Dawson D, Novak JM. Omega-3 fatty acid effect on alveolar bone loss in rats. J Dent Res. 2006:85:648-52.

35. Armstrong TA, Spears JW. Effect of dietary boron on growth performance, calcium and phosphorus metabolism, and bone mechanical properties in growing barrows. J Anim Sci. 2001; 79:3120-7.

36. Hinge M, Lund ED, Brandslund I, Plesner T, Madsen JS. Patient pools and the use of "patient means" are valuable tools in quality control illustrated by a bone-specific alkaline phosphatase assay. Clin Chem Lab Med. 2016; 54:403-6.

37. Kuroda T, Ohta H, Onoe Y, Tsugawa N, Shiraki M. Intake of omega-3 fatty acids contributes to bone mineral density at the hip in a younger Japanese female population. Osteoporos Int. 2017; 28:2887-91.

38. Watkins BA, Li Y, Lippman HE, Feng S. Modulatory effect of omega-3 polyunsaturated fatty acids on osteoblast function and bone metabolism. Prostaglandins Leukot Essent Fatty Acids. 2003; 68:387-98. 